\title{
How does decisional capacity evolve with normal cognitive aging: systematic review of the literature
}

\author{
Thomas Tannou ${ }^{1,2,3}$ (D) Séverine Koeberlé ${ }^{1,2} \cdot$ Régis Aubry $^{1,2,3} \cdot$ Emmanuel Haffen $^{3}$
}

Received: 21 May 2019 / Accepted: 1 October 2019 / Published online: 12 October 2019

(c) The Author(s) 2019

\section{Key summary points}

Aim The complexity of decision-making involves many neurological functions and structures which are potentially altered by cognitive aging.

Findings Our systematic review shows a decrease in processing speed in normal aging, usually compensated by experience. Nevertheless, in the case of decisions that cannot be based on previous experience, decision-making will be more difficult for older adults. Compared to younger adults, older ones will be more inclined to maintain existing achievements than try to gain potential benefits.

Message Decision-making supports should take into account age-related characteristics to facilitate informed decision-making.

\begin{abstract}
Purpose Aging is associated with increased needs related to complex decisions, particularly in medical and social issues. However, the complexity of decision-making involves many neurological functions and structures which are potentially altered by cognitive aging.

Methodology A systematic review was conducted in accordance with PRISMA guidelines to examine changes in decisionmaking occurring in normal cognitive aging. The keywords "decision making" and "normal aging" were used to find the clinical studies and literature reviews focused on these changes.

Results A total of 97 articles were considered in the review, and ultimately 40 articles were selected, including 30 studies and 10 literature reviews. The data from these studies were of uneven quality and too disparate to allow meta-analysis according to PRISMA criteria. Nevertheless, a key result of the analysis is the decrease of processing speed with aging. In ambiguous decision-making situations, the alteration of the ventromedial system is associated with changes in motivation profiles. These changes can be compensated by experience. However, difficulties arise for older adults in the case of one-off decisions, which are very common in the medical or medico-social domains.

Conclusions Cognitive aging is associated with a slowdown in processing speed of decision-making, especially in ambiguous situations. However, decision-making processes which are based on experience and cases in which sufficient time is available are less affected by aging. These results highlight the relativity of decision-making capacities in cognitive aging.
\end{abstract}

Keywords Decision making $\cdot$ Aging $\cdot$ Executive function $\cdot$ Motivation $\cdot$ Prefrontal cortex

Thomas Tannou

ttannou@chu-besancon.fr

1 Geriatrics Department, University Hospital of Besançon, 25000 Besançon, France

2 Equipe "Ethique et Progrès médical" - Clinical Investigation Centre CIC-IT 808 INSERM, University Hospital of Besançon, 25000 Besançon, France

3 Laboratoire de Neurosciences Intégratives et Cliniques EA481, Université Bourgogne Franche-Comté, 25000 Besançon, France 


\section{Introduction}

The aging of the population [1] has complexified the management of polypathology, as frailty and complex interactions between functional, psychological and social problems [2] are associated with an increase in the use of healthcare services and frequent hospitalizations [3]. These, in turn, inevitably require patients to make a large number of health decisions, as they need to choose between therapeutic strategies or address medico-social issues. According to the different legislations related to the patient's freedom of decision, each medical procedure must be subject to the consent of the patient, if he or she has the capacity to give consent $[4,5]$. All health decisions are explicitly based on free and informed consent, which requires both cognitive autonomy and decision-making abilities [6]. Thus, a complex phenomenon such as decision-making is particularly and frequently solicited during aging. Seniors, whose decision-making processes have been modified by aging, may potentially make uninformed choices. Consequences of these difficulties in decision-making do not only concern the medical field. They also impact daily life situations and, therefore, influence economic activities related to aging.

The complexity of decision-making lies in the simultaneous consideration of all available options. Each option is assigned with subjective value and potential risks. The choice of an option must then occur and involves executive processes. Finally, there is a retrospective reassessment, i.e. a comparison of the result obtained with the expected result [7]. The entire process requires the mobilization of attentional resources, working memory and executive functions. The data related to options, values and risks must be processed quickly. The choice is also made in relation to the memory of similar events that were previously experienced or learned, thus giving rise to an informed decision [8].

The uncertainty level associated with decision-making allow us to differentiate between three categories of decision-making in neuropsychology [9]: decision-making under certainty, decision-making under risk, and decision-making under ambiguity. In the first category, the decision is only based on certain known parameters. In the following two categories, decision-making processes are involved for risk assessment and mobilization of judgment skills [10, 11]. In the "under-risk" decision-making model, the probability of the risk occurring is known in advance and can be evaluated on the basis of experience. In the "under-ambiguity" model, decision-making is based on personal and theoretical projections. Decision-making models in complex situations refer to under-risk and under-ambiguity models [12].

Among the hypotheses put forward in the field of cognitive aging, some researchers raised the question of agerelated functional changes affecting mental processes and anatomical or neurobiological structures or circuits of decision-making $[13,14]$. Age-related changes concern cognition, emotions, motivation and neural subtracts [15], and mainly occur in the prefrontal cortex [16]. These modifications alter decision-making capacities during aging [17]. Several questions remain, however, as to how decisional autonomy could be better assessed in older adults.

To draw a more global picture of physiological modifications occurring in decision-making with aging, we performed a systematic review of the literature. We explored this question in terms of neurological function and performance, in neuropsychological and behavioural tasks. Our review specifically focused on the function of the prefrontal cortex.

\section{Methodology}

\section{Search strategy}

A bibliographic search was performed in the following databases: PubMed (Medline), Psych'Info and the Cochrane Library. The search included all articles and reviews published up to August 31,2018, without restriction on the start date and language. The search strategy combined the terms "Decision-making" AND "normal aging", without limiting the fields in which these terms appeared.

\section{Selection of publications for inclusion}

The review was performed in accordance with the PRISMA guidelines [18]. Two researchers (SK and TT) independently reviewed all the results of the initial search. After removing duplicates, titles and abstracts were reviewed independently by the two reviewers to select suitable publications for fulltext review. After reviewing the list of search results, the reviewers pooled their results. In case of discordance, the abstract was reviewed again and discussed by both reviewers, and then presented to a third reviewer (RA), until consensus was reached. Then, the lead author (TT) reviewed all the selected articles and extracted all the data pertaining to the understanding of potential changes in decisionmaking processes during physiological aging. The quality of the studies included was assessed using the Newcastle-Ottawa scale (NOS) [19]. NOS scores of $\geq 7$ were given to high-quality studies, and scores of 5-6 for publications of moderate quality. Details of quality criteria are available in Appendix 1.

\section{Inclusion criteria}

We included any clinical study or literature review dealing with changes to decision-making processes occurring during 
human physiological aging. We also included studies with healthy subjects comparing younger and older populations. In cases where patients with cognitive impairment were included in the study, the publication was considered in the present review if healthy older adults were also included and compared to younger ones.

The age criterion for aging was set at 65 years and over (unless a higher age threshold was already applied in the publication).

\section{Exclusion criteria}

Publications were excluded from the present review in the following cases:

- Publications that dealt with decision-making by medical staff, about patients' choices and associated processes (e.g. advance directives, surrogates, power of attorney for health, etc.). Indeed, a semantic bias in the keywords led to the inclusion, under the term "Medical decision-making", of both the decision-making processes of patients in medical strategies and the decisions taken by medical teams regarding therapeutic strategies associated with aging. The second situation does not correspond to our field of interest;

- Animal studies;

- Studies on the effect of aging on memory functions, if the studies were not associated with decision-making or analysis of executive functions;

- Studies on the effects of aging on non-cognitive functions (e.g. motor or sensory functions);

- Viewpoint articles, or theoretical articles without analysis of the literature.

\section{Results}

\section{Selection of articles for analysis}

A total of 145 articles were first identified based on the keywords "Decision-making" AND "normal aging". From these, 48 duplicates were excluded. A screening of the titles and abstracts of the remaining 97 articles led to the exclusion of 59 of these publications, and 38 articles were consulted in full and selected for inclusion in the analysis. After consideration of the reference lists of these articles, 14 other studies were identified and included.

During the analysis of the ful-text version, 12 articles were subsequently removed based on exclusion criteria (study of aging in association with neurodegenerative disease, book chapters, and one article was a doctoral thesis from the United States and we were unable to obtain a copy of the full thesis).

Thus, the final analysis included 40 articles (see flowchart, Fig. 1). The final selection included both original research articles (30 articles, see Table 1) and literature reviews (10 articles, see Table 2 ).

\section{Analysis of included articles}

The articles included in this review covered three types of analyses: (1) functional or experimental analyses of certain types of decision-making, as assessed by specific neuropsychiatric tests, notably those assessing frontal lobe functions; (2) neurofunctional analyses involving imaging techniques to track the activation of certain brain regions during decisionmaking; (3) Behavioural studies that analysed the impact of aging on decision-making processes in real-life.

\section{Frontal lobe disorders}

\section{Alteration of processing speed}

The first element that emerges from the literature is that frontal areas are the most affected by atrophy in aging [20]. Atrophy is clinically corroborated by an alteration of cognitive abilities, particularly executive functions. Various studies have demonstrated that verbal fluency, attention span, working memory and planning skills [21-28] also show an age-related decline. The performance of inhibition tasks is particularly affected [21, 29]. The literature consistently reports alterations in the Stroop and the Go/No Go tests in aging, illustrating difficulties associated with inhibition and the use of working memory [29-31]. Finally, during ocular follow-up tests, which involve the visual cortex and working memory, a weaker performance is found during initiation tests, with an overall slowing of cognitive processes that is not caused by focal lesions [32].

Yet, when the speed of information processing is controlled in clinical research, the cognitive alterations previously described are significantly reduced $[22,23,25,30$, 33-36]. This is particularly true for tasks requiring mental flexibility, in which the decrease in processing speed is more prominent than difficulties in the analysis [25, 33]. The reduction of processing speed would primarily explain the alteration of executive functions outlined in aging.

To better understand the causes of this decrease in processing speed, Dumas et al. [24] hypothesized that the decrease would be related to alterations in occipitotemporal areas. The effects of these alterations would be more or less marked depending on the possibility to recruit prefrontal circuits to compensate for performance difficulties, particularly in working memory. 
Fig. 1 Flowchart

Keywords : "Decision Making" and "Normal aging"

1. Identification of suitable publications:

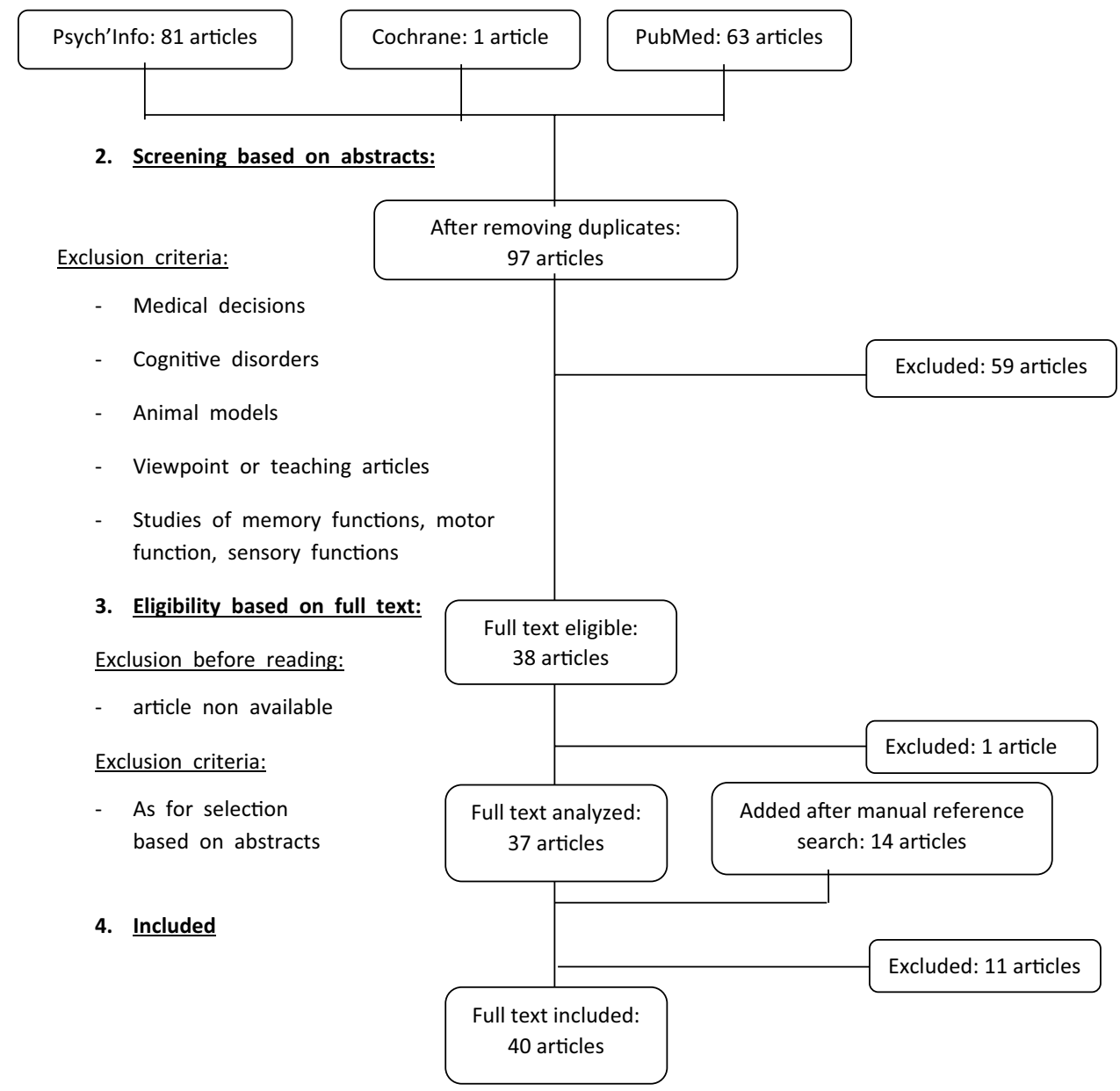

Functional MRI studies have been carried out to highlight this compensation [20]. These studies have shown a posterior-anterior shift of functional activations during attention tasks and tasks that require the use of working memory. Thus, there is less stress on occipito-temporal areas, in favour of prefrontal areas [24]. The latter are over-stimulated during the performance of cognitive tasks in older subjects, compared to younger ones. This shift is more pronounced when the task is new, complex and requires inhibitory control [37], and could indicate a compensatory phenomenon. The posterior-anterior shift is reduced as soon as the stimulation is no longer new, and would explain how lifetime experience in decision-making and problem solving can enhance processing speed [38].

\section{Alteration of prospective memory}

A second element highlighted in this review is the alteration of prospective memory, particularly in complex situations and multi-tasking [39]. However, there is no hippocampal dysfunction in patients who do not develop secondary neurocognitive disorders [24]. In a trial controlling cognitive deceleration factors (modelled via the Trail Making Test), Kim et al. [23] also demonstrated that age is not significantly associated with a decrease in auditory or verbal memory. However, visuo-spatial memory processes appear to be altered by age, independently of the slowing of cognitive processing speed [23].

\section{Targeted study of decision-making processes}

\section{Decision-making models}

To better study the impact of aging processes on cognitive changes, we will apply decision-making analysis methods that are traditionally used in neuropsychology. This involves 2 types of decision-making [11]: 


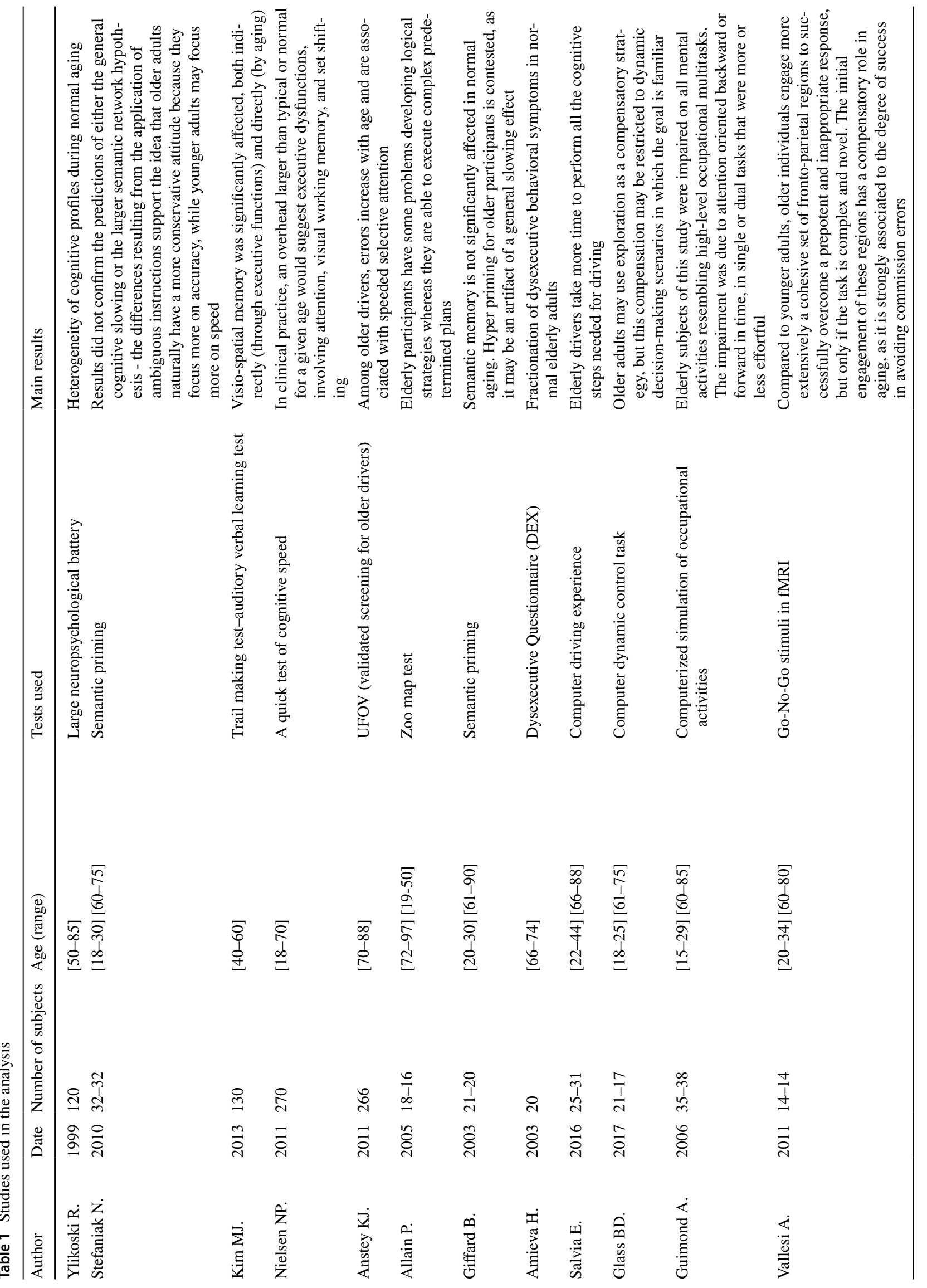




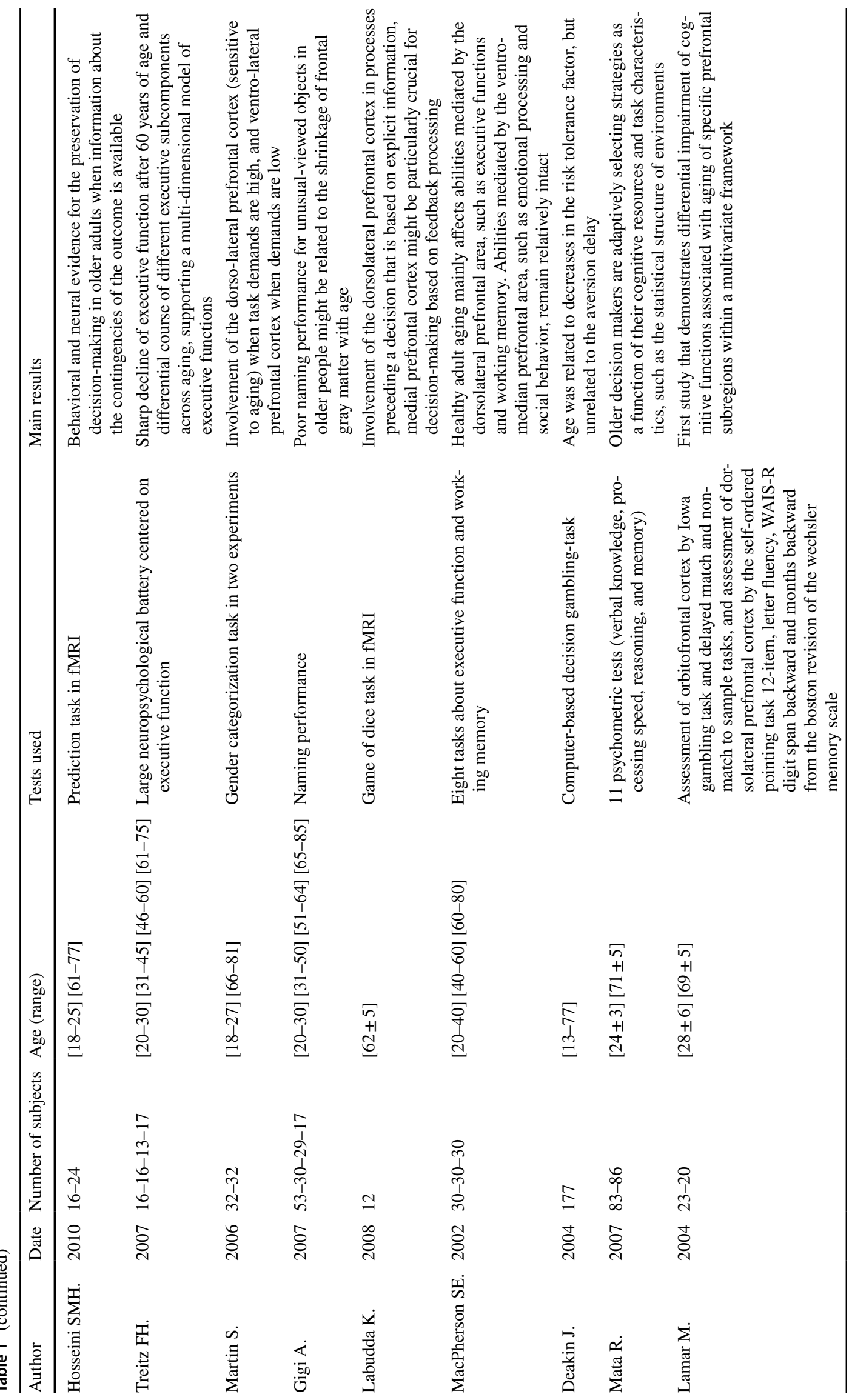




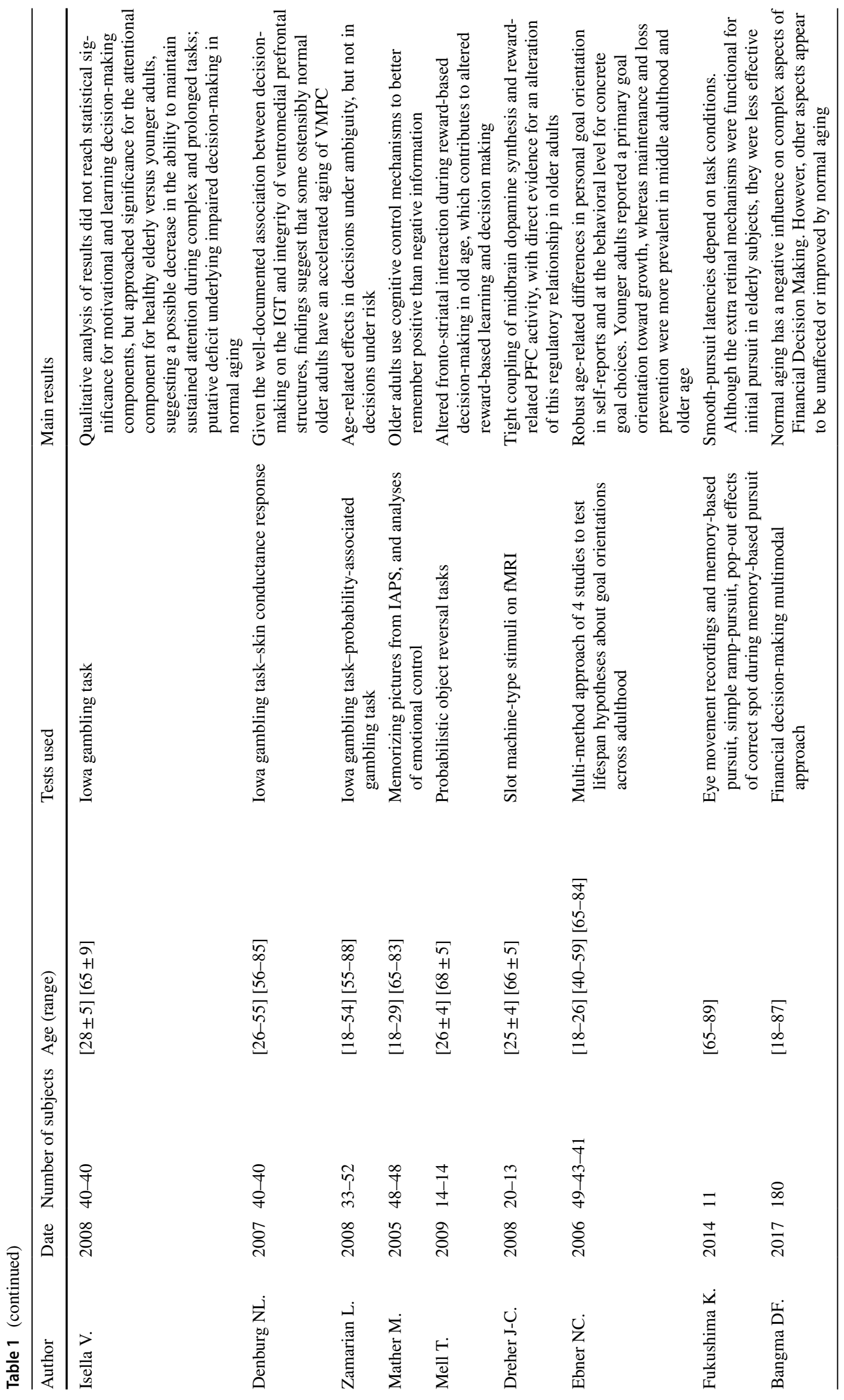


Table 2 Reviews used in the analysis

- the so-called "under risk" model, which is traditionally associated with dorsolateral functions [40], in particular with processing speed and working memory.

The main neuropsychological tests used in the selected studies are the Wisconsin Card Sorting Task and the Game of Dice Task. In these tests, it is found that elements of slow decision-making are explained by the slowing down of processing speed. Nevertheless, as soon as the rules are given and the learning speed is smoothed, there is no alteration in the decision-making modalities in this type of model [20,41]. Some studies also show that the experience acquired is a factor facilitating decision-making in older subjects when the situation is based on the acquired experience, but this experience does not facilitate decisions in new situations [42].

- The "under-ambiguity" model involves dorsolateral functions [43], particularly through the use of working memory, but also ventromedial pathways, especially straight, and limbic pathways which are activated during the regulation of emotional processes [20,44].

The studies on the under-ambiguity model are very controversial and question the pertinence of this model. The main tests used are the Match-to-Sample Task [45, 46] and the Iowa Gambling Task [IGT] [47]. Interpretations diverge between studies [47-49], particularly for the IGT, because once the operating rules are acquired, this test is very close to a risky decision-making model, and the results improve [50].

Nevertheless, the targeted study of decision-making processes, assessed with specialized neuropsychological tests or functional neuroimaging, confirms the general conclusions related to the impact of processing speed and benefits of learning, which might help to compensate for age-related decreases of processing speed.

\section{Decision-making in complex situations}

Risk aversion was also highlighted in some studies [44, 51, 52]. In complex decisions, there is a change in the cost-benefit analysis [35], and decisions reveal the development of strategies aiming to prevent losses [53]. According to some authors, the focus on loss prevention could be explained by a decreased integration of consequences associated with previous decisions and could be linked to a slowdown of implicit learning phenomena [20, 41]. Loss-prevention strategies are particularly noticeable when decision-making requires marked attention or involves emotional phenomena [21, 47, 54].

Indeed, in complex situations, decision-making goes beyond the scope of executive functions and includes emotional and motivational circuits [55]. In particular, reward circuits are associated with this type of decision-making.

However, in cerebral aging, there is a modification of the activation of the ventral striatum [56] with:

- a loss of information and learning associated with reward.

- a reinforcement of the activity of reward circuits, especially in the ventral striatum, for the preservation of learned strategies.

This could be explained by a decrease in dopaminergic synthesis and expression during aging [57].

These modifications of ventral striatum activations are potentially linked to the impact of motivational circuits on learning in ambiguous decision-making strategies [31]. Indeed, the strategy of loss prevention, which is prioritized over gain optimization in older adults, can be explained by an acquired behavioral adaptation to declining capacities with aging [58] and could underlie the phenomenon of positivity [53].

Thus, when older subjects make complex decisions involving the comparison of potential benefits, they will be more sensitive to losses. Therefore, this can lead them to adapt their strategies according to the risk of loss and choose more conservative decision-making strategies.

\section{Macro-behavioural changes}

In addition to the functional and anatomical elements previously highlighted, some data must be taken into account in the modifications that are specific to decision-making in complex situations in aging.

Several studies have focused on the context of decisionmaking and report variations according to:

- The timing of decision-making in relation to circadian rhythm. Indeed, maximum cognitive availability of older adults is no longer in the afternoon or evening (as in younger adults), but rather in the morning [22].

- The environmental context of decision-making (sounds, number of proposals, clarity of information, the impression of familiar information, etc.). The influence 
of environmental conditions can be compensated by appropriate measures (e.g. note-taking) [22].

Behavioural studies, particularly neuro-economic studies, show that the habit of making quick decisions is based on experience (including previous professional experience) and affect, rather than reasoning [22, 39], exposing older subjects to misleading advertisements [47].

Finally, the literature also mentions the benefit of physical activity over inactivity for all aging processes [59], probably through cardiovascular benefits.

\section{Discussion}

Our review highlights changes in decision-making patterns and processes during cognitive aging. These changes vary greatly depending on the context, motivational factors and impact of risks. Our analysis shows that:

- Cognitive aging is associated with a decline of components of executive functions, particularly processing speed and reactivity of working memory. This is due to alterations in the dorsolateral prefrontal cortex. In some cases, these alterations can be compensated by previous knowledge associated with similar experiences. However, when faced with new and unfamiliar situations, older adults take more time to comprehend the situation than younger ones. However, as soon as the rules of the situation are established, this difference between younger and older adults disappears;

- When decisions are made in situations where the consequences are unknown, different interpretations are found in the literature. Classically, these situations are explored with "under-ambiguity" decision-making tests. Decision-making modalities in these cases involve both executive functions (particularly the dorsolateral cortex), but also motivation and reward processes. These processes have been previously associated with ventromedial and limbic structures. There are considerably fewer studies in this field and their results are sometimes ambiguous. In general, they tend to show that aging is associated with a change in strategy: reduction or prevention of losses is favored over the optimization of gains. Choices resulting from this shift are influenced by the individual motivation profile in each particular situation.

Therefore, it seems that, in aging, there may be a partial decline of decision-making skills for complex and new situations, which might influence the level of cognitive autonomy. Cognitive autonomy would thus be maintained as far as it is possible to recall an appropriate experience, but it would be put in difficulty in the event of a complex and unprecedented situation.

The strength of our literature review lies in the inclusion of both research articles and the analysis of previous reviews, the last of which was published in 2016. Thus, the inclusion of these literature reviews allowed the integration of articles that would not have been found with our keyword screening. The analysis of these reviews also extended the scope of the study to the full complexity of the decisionmaking process. Indeed, each of the previous publications that we analyzed had a more targeted approach, focusing either on neuropsychological processes, neurophysiological processes approached by functional imaging, or macroscopic processes (in particular neuro-economic processes). The originality of our approach is, on the one hand, the update on the issue, but also, and above all, on the other hand, the global approach covering several fields that are usually approached separately, and discuss their clinical impact in current clinical situations.

Nevertheless, our literature review has several limitations:

- The choice of the keywords "normal aging" leads to a reduction in the scope of "aging" or "ageing". However, there is no MeSH term associated with physiological aging, and "aging" mainly included pathological aging. To ensure that we cover the entire field of non-pathological aging, we have chosen to include in our review all previous systematic reviews using the keyword "normal aging". This gave us the opportunity to consult their references and include articles that otherwise would have been missed due to the restriction associated with our keywords.

- The general element that emerges from previous studies is the extreme heterogeneity of cognitive profiles in aging, and the difficulty to differentiate the profile of physiological aging from that of pathological aging at a sub-clinical stage [24, 34]. In addition, the notion of cognitive reserve and education are associated with experience-driven differentiation of neuropsychological activities, whose influence needs to be dissociated from neuro-anatomical characteristics [60]. In addition, training effects may occur, and a recent study seems to show a modification of Iowa Gambling Task response profiles in cases of specific attentional training [61].

- In addition, in the clinical studies included in our review, even if patients with neurocognitive pathological alterations were excluded, only one study prevented interference with neurodegenerative diseases not yet diagnosed. The researchers did a follow-up of participants to screen for neurodegenerative diseases. In the majority of studies, it was not verified if participants presented a neurocognitive pathology. This should have been made prospectively to be sure that they did not present, at the 
time of their inclusion, a neurocognitive pathology at an infra-clinical stage. Indeed, neurodegenerative pathologies impact decision-making capacities [62-65]. Nevertheless, it appears that tests focused on decision-making processes can remain informative even in the mild stages of these diseases, and the impact of mild pathological cases on overall results is limited, as shown in Jacus et al. [66].

- Another limitation is the relatively young age of the populations included. Indeed, to avoid bias related to neurodegenerative pathologies, the majority of studies included patients aged between 65 and 75 years. Given the aging of the populations and an average age of transition towards dependency at 83 years [67], this is poorly representative of older populations having to make complex medical and medico-social choices [68].

- Finally, for clinical studies, there is a wide variety of tests used, without homogeneity on the neurological processes studied. This is probably the most important limitation of our review, which prevented us from doing a metaanalysis, according to the PRISMA guidelines. Among these studies, there are several monetary models representing changes of perception with age, and their impact on decision-making is different from that of social or medical models [69]. Thus, our review reveals a variation in decision-making models according to what is taken into account: motivation or risk, and specificities related to the areas of daily life affected by these decisions (money, health, social) [53].

The limitations expressed, in particular the lack of homogeneity of tests and populations, which does not allow for a meta-analysis of the data obtained in these studies.

Nevertheless, in the light of this literature review, there is a consensus that decision-making is possible in physiological aging, including in complex and new situations. However, several constraints need to be taken into account:

1. It is necessary to allow time for decision-making.

Indeed, given the decrease in processing speed, additional time is required for decision-making. A way to facilitate decision-making is to reduce factors that can affect this decrease in processing speed, whether external (environment, number of proposals, etc.) or internal (emotional appeal, disaffection, etc.).

Reformulation can be helpful to clarify the available options and support rational arguments, to avoid emotional decision-making.

2. It is necessary to take into account the motivational profile to present an appropriate argument. Indeed, when a decision is made in a known situation, older persons will easily rely on experience [70]. However, when decisions involve new situations, the arguments presented will be essential. However, given that sensitivity to loss prevention increases, and attractiveness of earnings decrease as we age, it is likely that the presentation of an earningbased motivation formula might not be as effective as the choice of the appropriate interlocutor [69].

However, the literature on these elements and complex situations is scarce. More studies that simultaneously analyze patients' arguments and physiological behavioural responses are needed, particularly for the ventromedial and limbic systems (motivation, risk taking) [47, 71] which are the most debated substrates for ambiguous decision-making.

This literature review reinforces the need for future studies to identify, describe and understand decision-making phenomena in patients aged 75 years and older, to better understand the relativity of decision-making autonomy.

\section{Conclusion}

Decision-making, as other cognitive abilities, is affected by an age-related slowdown in the speed of information processing. However, cognitive capacity can be preserved and adequately expressed if the person is provided with enough time and clear explanations. In this perspective, it is necessary to take the appropriate time, for example in medical consultation, and have the patient reformulate to ensure that the elements have been properly integrated. This allows, in physiological aging, that decision-making respects patient's autonomy when decisions are based on experience.

However, when decisions need to be made in situations of uncertainty, cognitive aging is associated with changes in the functioning of the ventromedial system which are linked to decision-making difficulties. These difficulties can be compensated by learning but become a challenge in complex unique decision-making situations, and are strongly impacted by motivational elements. Given that, older subjects are more sensitive to information related to the risk of loss than information related to potential benefits. This raises the question of how information is provided to older patients, and which parameters are used for decision-making.

It should be noted that several medical and medico-social decisions are based on ambiguous decision-making, and do not allow for compensation through learning, because they are usually one-off decisions (entry into institutions, surgery, etc.).

Like previous literature reviews, we question decisionmaking skills in older adults, particularly in situations of ambiguity, which is part of the most complex medical or medico-social situations affecting the older population. Thus, a fortiori, in the case of neurocognitive disorders with impaired executive functions, or in the case of the development of apathy, the question of cognitive and 
decision-making autonomy is predominant. However, it appears that it is in these situations of relative autonomy that the most complex decisions take place, particularly in relation to the limitation of care or institutionalization. Therefore, the notion of the relativity of decision-making capacity in cognitive aging needs to be addressed to fully understand specific limitations and solutions for this population. Comprehensive and analytical studies are, therefore, needed on the subject.

Acknowledgements This work was supported by the Fondation Bettencourt Schueller (Support 2017-2019). Thanks to Helli Raptis (CR IUGM, Montreal, Qc, CANADA) for English Reviewing.

Authors contribution The supervision of the systematic review was carried out by EH and RA. The PRISMA reviewing was made by SK and TT, and RA in case of discordance. The main author of the article was TT.

\section{Compliance with ethical standards}

Conflict of interest The authors declare no conflict of interest.

Ethical approval This article does not contain any studies with human participants performed by any of the authors.

Informed consent For this type of study, formal consent is not required.

Open Access This article is distributed under the terms of the Creative Commons Attribution 4.0 International License (http://creativeco mmons.org/licenses/by/4.0/), which permits unrestricted use, distribution, and reproduction in any medium, provided you give appropriate credit to the original author(s) and the source, provide a link to the Creative Commons license, and indicate if changes were made.

\section{Appendix}

See Table 3.
Table 3 N.O.S. quality assessment of selected studies

\begin{tabular}{|c|c|c|c|c|c|}
\hline Author & Date & Selection (/4) & $\begin{array}{l}\text { Comparability } \\
\text { (/2) }\end{array}$ & Outcome (/3) & Total (/9) \\
\hline Ylikoski R. & 1999 & 4 & 1 & 2 & 7 \\
\hline Stefaniak N. & 2010 & 2 & 2 & 3 & 7 \\
\hline Kim MJ. & 2013 & 2 & 1 & 2 & 6 \\
\hline Nielsen NP. & 2011 & 4 & 2 & 2 & 8 \\
\hline Anstey KJ. & 2011 & 3 & 2 & 3 & 8 \\
\hline Allain P. & 2005 & 2 & 2 & 2 & 6 \\
\hline Giffard B. & 2003 & 3 & 2 & 2 & 7 \\
\hline Amieva $\mathrm{H}$. & 2003 & 3 & 2 & 2 & 7 \\
\hline Salvia E. & 2016 & 3 & 2 & 2 & 6 \\
\hline Glass BD. & 2017 & 3 & 1 & 3 & 7 \\
\hline Guimond A. & 2006 & 2 & 1 & 3 & 6 \\
\hline Vallesi A. & 2011 & 3 & 2 & 3 & 8 \\
\hline Hosseini SMH. & 2010 & 2 & 1 & 3 & 6 \\
\hline Treitz FH. & 2007 & 3 & 2 & 3 & 8 \\
\hline Martin S. & 2006 & 2 & 2 & 2 & 6 \\
\hline Gigi A. & 2007 & 2 & 2 & 2 & 6 \\
\hline Labudda K. & 2008 & 3 & 2 & 2 & 7 \\
\hline MacPherson SE. & 2002 & 4 & 2 & 3 & 9 \\
\hline Deakin J. & 2004 & 3 & 2 & 2 & 7 \\
\hline Mata R. & 2007 & 4 & 2 & 3 & 9 \\
\hline Lamar M. & 2004 & 3 & 2 & 2 & 7 \\
\hline Isella V. & 2008 & 2 & 2 & 2 & 6 \\
\hline Denburg NL. & 2007 & 3 & 2 & 3 & 8 \\
\hline Zamarian L. & 2008 & 3 & 2 & 3 & 8 \\
\hline Mather M. & 2005 & 2 & 1 & 2 & 5 \\
\hline Mell T. & 2009 & 3 & 2 & 3 & 8 \\
\hline Dreher J-C. & 2008 & 3 & 2 & 3 & 8 \\
\hline Ebner NC. & 2006 & 2 & 1 & 3 & 6 \\
\hline Fukushima K. & 2014 & 3 & 1 & 3 & 7 \\
\hline Bangma DF. & 2017 & 3 & 2 & 3 & 8 \\
\hline
\end{tabular}




\section{References}

1. Department of Economic and Social Affairs, Population Division (2017) World population ageing 2017-highlights. United Nations. Report No.: (ST/ESA/SER.A/397)

2. Schaink AK, Kuluski K, Lyons RF, Fortin M, Jadad AR, Upshur $R$ et al (2012) A scoping review and thematic classification of patient complexity: offering a unifying framework. J Comorbidity. 2:1-9

3. Smith SM, O'Dowd T (2007) Chronic diseases: what happens when they come in multiples? Br J Gen Pract

4. Appelbaum PS (2007) Assessment of patients' competence to consent to treatment. N Engl J Med 357:1834-1840

5. Berg JW, Appelbaum PS, Lidz CW, Parker LS (2001) Informed consent: legal theory and clinical practice, 2nd edn. Oxford University Press, Oxford

6. Beauchamp TL, Childress JF (2001) Principles of biomedical ethics. Oxford University Press, Oxford

7. Gleichgerrcht E, Ibáñez A, Roca M, Torralva T, Manes F (2010) Decision-making cognition in neurodegenerative diseases. Nat Rev Neurol. 6:611

8. Baron J (2008) Thinking and deciding, 4th edn. Cambridge University Press, New York

9. Allain P (2013) La prise de décision: aspects théoriques, neuroanatomie et évaluation. Rev Neuropsychol. 5:69-81

10. Escudier F, Léveillé E, Charbonneau S, Cole J, Hudon C, Bédirian V et al (2016) Evaluating decision-making: validation and regression-based normative data of the judgment assessment tool. Arch Clin Neuropsychol. 31:829-838

11. Bechara A, Damasio H, Tranel D, Damasio AR (2005) The Iowa Gambling Task and the somatic marker hypothesis: some questions and answers. Trends Cogn Sci. 9:159-162

12. Bechara A, Damasio H, Tranel D, Damasio AR (1997) Deciding advantageously before knowing the advantageous strategy. Science 275:1293-1295

13. Mata R, Hertwig R (2011) How to model age-related motivational reorientations in risky choice. Hum Dev 54:368-375

14. Boyle PA, Yu L, Wilson RS, Gamble K, Buchman AS, Bennett DA (2012) Poor decision making is a consequence of cognitive decline among older persons without Alzheimer's disease or mild cognitive impairment. PLoS ONE 7:e43647

15. Löckenhoff CE (2018) Aging and decision-making: a conceptual framework for future research-a mini-review. Gerontology. 64:140-148

16. Salami A, Rieckmann A, Fischer H, Bäckman L (2014) A multivariate analysis of age-related differences in functional networks supporting conflict resolution. NeuroImage. 86:150-163

17. Price A, McCormack R, Wiseman T, Hotopf M (2014) Concepts of mental capacity for patients requesting assisted suicide: a qualitative analysis of expert evidence presented to the Commission on Assisted Dying. BMC Med Ethics. 15:32

18. Moher D, Shamseer L, Clarke M, Ghersi D, Liberati A, Petticrew $M$ et al (2015) Preferred reporting items for systematic review and meta-analysis protocols (PRISMA-P) 2015 statement. Syst Rev. 4:1

19. Wells GA. The Newcastle-Ottawa Scale (NOS) for assessing the quality of nonrandomised studies in meta-analyses. http://www. ohri.ca/programs/clinical_epidemiology/oxford.asp. Accessed 15 Aug 2019

20. Hosseini SMH, Rostami M, Yomogida Y, Takahashi M, Tsukiura T, Kawashima R (2010) Aging and decision making under uncertainty: behavioral and neural evidence for the preservation of decision making in the absence of learning in old age. NeuroImage. 52:1514-1520
21. Calso C, Besnard J, Allain P (2016) Le vieillissement normal des fonctions cognitives normales. Geriatr Psychol Neuropsychiatr Vieil. 14:77-85

22. Carpenter SM, Yoon C (2011) Aging and consumer decision making. Ann N Y Acad Sci 1235:E1-12

23. Kim M-J, Kwon JS, Shin M-S (2013) Mediating effect of executive function on memory in normal aging adults. Psychiatry Investig. 10:108-114

24. Dumas JA (2015) What is normal cognitive aging? evidence from task-based functional neuroimaging. Curr Behav Neurosci Rep 2:256-261

25. Nielsen NP, Wiig EH (2011) An additive model for relations between AQT single- and dual-dimension naming speed. Percept Mot Skills 112:499-508

26. Anstey KJ, Wood J (2011) Chronological age and age-related cognitive deficits are associated with an increase in multiple types of driving errors in late life. Neuropsychology. 25:613-621

27. Gigi A, Babai R, Katzav E, Atkins S, Hendler T (2007) Prefrontal and parietal regions are involved in naming of objects seen from unusual viewpoints. Behav Neurosci 121:836-844

28. Allain P, Nicoleau S, Pinon K, Etcharry-Bouyx F, Barré J, Berrut $\mathrm{G}$ et al (2005) Executive functioning in normal aging: a study of action planning using the Zoo Map Test. Brain Cogn 57:4-7

29. Treitz FH, Heyder K, Daum I (2007) Differential course of executive control changes during normal aging. Neuropsychol Dev Cogn B Aging Neuropsychol Cogn. 14:370-393

30. Amieva H, Phillips L, Della Sala S (2003) Behavioral dysexecutive symptoms in normal aging. Brain Cogn 53:129-132

31. Martin S, Brouillet D, Guerdoux E, Tarrago R (2006) Inhibition and resource capacity during normal aging: a confrontation of the dorsal-ventral and frontal models in a modified version of negative priming. L'Encephale 32:253-262

32. Fukushima K, Barnes GR, Ito N, Olley PM, Warabi T (2014) Normal aging affects movement execution but not visual motion working memory and decision-making delay during cue-dependent memory-based smooth-pursuit. Exp Brain Res 232:2369-2379

33. Giffard B, Desgranges B, Kerrouche N, Piolino P, Eustache F (2003) The hyperpriming phenomenon in normal aging: a consequence of cognitive slowing? Neuropsychology. 17:594-601

34. Ylikoski R, Ylikoski A, Keskivaara P, Tilvis R, Sulkava R, Erkinjuntti T (1999) Heterogeneity of cognitive profiles in aging: successful aging, normal aging, and individuals at risk for cognitive decline. Eur J Neurol 6:645-652

35. Zhu L, Walsh D, Hsu M (2012) Neuroeconomic measures of social decision-making across the lifespan. Front Neurosci. 6:128

36. Salvia E, Petit C, Champely S, Chomette R, Di Rienzo F, Collet C (2016) Effects of age and task load on drivers' response accuracy and reaction time when responding to traffic lights. Front Aging Neurosci. 8:169

37. Vallesi A, McIntosh AR, Stuss DT (2011) Overrecruitment in the aging brain as a function of task demands: evidence for a compensatory view. J Cogn Neurosci. 23:801-815

38. Glass BD, Osman M (2017) Positive explorers: modeling dynamic control in normal aging. Neuropsychol Dev Cogn B Aging Neuropsychol Cogn. 24:62-79

39. Guimond A, Braun CMJ, Rouleau I, Bélanger F, Godbout L (2006) Remembering the past and foreseeing the future while dealing with the present: a comparison of young adult and elderly cohorts on a multitask simulation of occupational activities. Exp Aging Res 32:363-380

40. Labudda K, Woermann FG, Mertens M, Pohlmann-Eden B, Markowitsch HJ, Brand M (2008) Neural correlates of decision making with explicit information about probabilities and incentives in elderly healthy subjects. Exp Brain Res 187:641-650

41. Brand M, Markowitsch HJ (2010) Aging and decision-making: a neurocognitive perspective. Gerontology. 56:319-324 
42. Mata R, Schooler LJ, Rieskamp J (2007) The aging decision maker: cognitive aging and the adaptive selection of decision strategies. Psychol Aging 22:796-810

43. Li X, Lu Z-L, D'Argembeau A, Ng M, Bechara A (2010) The Iowa Gambling Task in fMRI images. Hum Brain Mapp 31:410-423

44. Jacus J-P, Bayard S, Raffard S, Bonnoron S, Gely-Nargeot M-C (2012) Decision-making in normal and pathological aging. Geriatr Psychol Neuropsychiatr Vieil. 10:437-444

45. Lamar M, Resnick SM (2004) Aging and prefrontal functions: dissociating orbitofrontal and dorsolateral abilities. Neurobiol Aging 25:553-558

46. Isella V, Mapelli C, Morielli N, Pelati O, Franceschi M, Appollonio IM (2008) Age-related quantitative and qualitative changes in decision making ability. Behav Neurol. 19:59-63

47. Denburg NL, Cole CA, Hernandez M, Yamada TH, Tranel D, Bechara A et al (2007) The orbitofrontal cortex, real-world decision making, and normal aging. Ann N Y Acad Sci 1121:480-498

48. Jacus J-P, Bayard S, Raffard S, Gely-Nargeot M-C (2013) Decision-making in normal and pathological aging. Rev Neuropsychol Neurosci Cogn Clin. 5:93-105

49. Wiesiolek CC, Foss MP, Beserra Diniz PR (2014) Normal aging and decision-making: a systematic review of the literature of the last 10 years. J Bras Psiquiatr. 63:255-259

50. Zamarian L, Sinz H, Bonatti E, Gamboz N, Delazer M (2008) Normal aging affects decisions under ambiguity, but not decisions under risk. Neuropsychology. 22:645-657

51. MacPherson SE, Phillips LH, Della Sala S (2002) Age, executive function and social decision making: a dorsolateral prefrontal theory of cognitive aging. Psychol Aging 17:598-609

52. Deakin J, Aitken M, Robbins T, Sahakian BJ (2004) Risk taking during decision-making in normal volunteers changes with age. $\mathrm{J}$ Int Neuropsychol Soc. 10:590-598

53. Depping MK, Freund AM (2011) Normal aging and decision making: the role of motivation. Hum Dev 54:349-367

54. Bangma DF, Fuermaier ABM, Tucha L, Tucha O, Koerts J (2017) The effects of normal aging on multiple aspects of financial decision-making. PLoS ONE 12:e0182620

55. Mather M, Knight M (2005) Goal-directed memory: the role of cognitive control in older adults' emotional memory. Psychol Aging 20:554-570

56. Mell T, Wartenburger I, Marschner A, Villringer A, Reischies FM, Heekeren HR (2009) Altered function of ventral striatum during reward-based decision making in old age. Front Hum Neurosci. 3:34

57. Dreher J-C, Meyer-Lindenberg A, Kohn P, Berman KF (2008) Age-related changes in midbrain dopaminergic regulation of the human reward system. Proc Natl Acad Sci 105:15106-15111

58. Ebner NC, Freund AM, Baltes PB (2006) Developmental changes in personal goal orientation from young to late adulthood: from striving for gains to maintenance and prevention of losses. Psychol Aging 21:664-678

59. Renaud M, Bherer L (2005) L'impact de la condition physique sur le vieillissement cognitif. Psychol Neuropsychiatr Vieil. 3:199-206

60. Stefaniak N, Meulemans T, Willems S (2010) Semantic hyperpriming in normal aging: a consequence of instructions? Neuropsychol Dev Cogn B Aging Neuropsychol Cogn. 17:615-632

61. Schmicker M, Menze I, Koch D, Rumpf U, Müller P, Pelzer L et al (2019) Decision-making deficits in elderly can be alleviated by attention training. J Clin Med. 8:1131

62. Davis R, Ziomkowski MK, Veltkamp A (2017) Everyday decision making in individuals with early-stage Alzheimer's disease: an integrative review of the literature. Res Gerontol Nurs. 10:240-247

63. Alameda-Bailen JR, Salguero-Alcaniz MP, Merchan-Clavellino A, Paino-Quesada S (2017) Cognitive mechanisms in decisionmaking in patients with mild Alzheimer disease. Curr Alzheimer Res 14:1248-1255

64. de Siqueira ASS, Yokomizo JE, Jacob-Filho W, Yassuda MS, Aprahamian I (2017) Review of decision-making in game tasks in elderly participants with Alzheimer disease and mild cognitive impairment. Dement Geriatr Cogn Disord 43:81-88

65. Gold BT, Jiang Y, Jicha GA, Smith CD (2010) Functional response in ventral temporal cortex differentiates mild cognitive impairment from normal aging. Hum Brain Mapp 31:1249-1259

66. Jacus J-P, Gély-Nargeot M-C, Bayard S (2018) Ecological relevance of the Iowa gambling task in patients with Alzheimer's disease and mild cognitive impairment. Rev Neurol 174:327-336

67. Duée M, Rebillard C (2006) La dépendance des personnes âgées: une projection en 2040. Données Soc-Société Fr. 7:15

68. Kendig H, Gong CH, Cannon L, Browning C (2017) Preferences and predictors of aging in place: longitudinal evidence from Melbourne, Australia. J Hous Elder. 31:259-271

69. Liebherr M, Schiebener J, Averbeck H, Brand M (2017) Decision making under ambiguity and objective risk in higher age-a review on cognitive and emotional contributions. Front Psychol. $8: 2128$

70. Eberhardt W, Bruine de Bruin W, Strough J (2019) Age differences in financial decision making: the benefits of more experience and less negative emotions. J Behav Decis Mak. 32:79-93

71. Bechara A, Damasio H, Damasio AR, Lee GP (1999) Different contributions of the human amygdala and ventromedial prefrontal cortex to decision-making. J Neurosci 19:5473-5481

Publisher's Note Springer Nature remains neutral with regard to jurisdictional claims in published maps and institutional affiliations. 